\title{
Interactions of Environmental Pollutant Aromatic Amines with photoexcited states of Thiophene Substituted 1,3,4-Oxadiazole Derivative: Fluorescence quenching studies
}

G.H Malimath ( $\nabla$ gurukcd@gmail.com )

Karnatak Science College Dharwad https://orcid.org/0000-0001-9493-4549

Thippeswamya M.S

Government First Grade College

Lohit Naik

Christ University

C.V Maridevarmath

Government First Grade College

\section{Research Article}

Keywords: eFluorescence equenching, eStern-Volmer, e1,3,4-oxadizoles, DFT, Electron transfer

Posted Date: February 3rd, 2022

DOI: https://doi.org/10.21203/rs.3.rs-1260198/v1

License: (c) (1) This work is licensed under a Creative Commons Attribution 4.0 International License.

Read Full License 


\title{
Interactions of Environmental Pollutant Aromatic Amines with photoexcited states of Thiophene Substituted 1,3,4-Oxadiazole Derivative: Fluorescence quenching studies
}

\author{
Thippeswamy M.S ${ }^{a}$, Lohit Naik ${ }^{b}$, C.V. Maridevarmath ${ }^{c}$ and G.H. Malimath ${ }^{d^{*}}$ \\ ${ }^{a}$ Department of Physics, Government First Grade College, Harihara-577601, Karnataka, India \\ ${ }^{b}$ Department of Physics and Electronics, CHRIST (Deemed to be University), Bangalore-560029, \\ Karnataka, India \\ ${ }^{\mathrm{c}}$ Department of Physics, Government First Grade College, Hubballi-580032, Karnataka, India \\ ${ }^{\mathrm{d}}$ UG and PG Department of Physics, Karnatak Science College, Dharwad-580001, Karnataka, India \\ *Corresponding author E-mail: gurukcd@gmail.com
}

\begin{abstract}
:
In the present work, the fluorescence quenching of novel thiophene substituted 1,3,4oxadiazole derivative 2-(4-(4-vinylphenyl) phenyl)-5-(5-(4-vinylphenyl)thiophen-2-yl)-1,3,4oxadiazole (TSO) by five different environmental pollutant aromatic amine derivatives like 2,4-dimethylaniline, 3-chloroaniline, 4-chloroaniline, o-anisidine, and m-toluidine has been studied at room temperature through steady-state, and time-resolved methods. The fluorescence intensity of fluorophore TSO decreased as the concentration of aromatic amines increased. The fluorescence quenching mechanism between TSO and aromatic amines is analysed through Stern-Volmer plots. The steady state Stern-Volmer plots were found to be nonlinear with a positive deviation, whereas time resolved Stern-Volmer plots show linearity with an increase in quencher concentration. Further, the Stern-Volmer constants $\left(\mathrm{k}_{\mathrm{sv}}\right)$, quenching rate parameters $\left(\mathrm{k}_{\mathrm{q}}\right)$, static quenching constant $(\mathrm{V})$ and radius of the sphere of action ( $r$ ) are calculated. The magnitude of these parameters suggests that the sphere of action static quenching model is responsible for the overall quenching mechanism. Further, with the use of finite sink approximation model to check these bimolecular reactions as diffusionlimited and to estimate independently S-V constant, the distance parameter ( $\left.\mathrm{R}^{\prime}\right)$, mutual diffusion coefficient (D), and diffusion controlled parameter $\left(\mathrm{k}_{\mathrm{d}}\right)$ were calculated. These values indicate that the bimolecular quenching reactions are due to the collective effect of dynamic and static quenching mechanisms and these results are confirmed by the time-resolved
\end{abstract}


measurements. The higher values of Gibb's free energy determined from the Rehm-Weller relation through cyclic voltammetry studies suggests that, the fluorescence quenching is due to electron transfer and the same is confirmed by the DFT theoretical studies. Further, the binding equilibria analysis confirm, 1:1 stoichiometry ratio between fluorophore and quencher and also strong binding between the fluorophore and aromatic amines.

Keywords: Fluorescence quenching; Stern-Volmer; 1,3,4-oxadizoles; DFT; Electron transfer

\section{Introduction}

For many years, the detection of aromatic amines has become very important, because they have been considered as severe destroyers of environmental ecological equilibrium and toxic to human health via breathing, skin contact, etc. The detection is also important in terms of monitoring industrial and environmental pollution, diagnosis of certain diseases, for checking the quality of food products, etc. The vapours of aromatic amines can diffuse into the atmosphere from foul water, car exhaust, incineration of garbage, construction materials, industrial emissions, cigarette smoke, etc. Aniline and its derivatives are of high toxicity to all living organisms even at very low concentrations and have been considered as a potential carcinogen and are listed as Group 3 root causes by "The International Agency for Research on Cancer" (IARC) [1-3]. It has been reported that, acute inhalation exposure to high levels of aniline and its derivatives can lead to lung cancer in human beings. Further, detection of carcinogenic organic compounds like aromatic amines, o-toluidine, nitro aromatics, etc. is important since tobacco smokes contains a large number of them and are known to cause bladder cancer. However, in spite of these, aromatic amines have been widely used in cosmetics, medicines, pesticides, dye intermediates, herbicides, rubber, coal conversion and various industries like chemical, pharmaceutical, military industries, etc. Therefore, developing highly sensitive, selective and efficient detection methods for aromatic amines has gained the large attention of researchers around the world for the last so many years [4-6].

For the detection of aromatic amines various analytical methods like gas chromatography-mass spectrometry (GC-MS), high performance liquid chromatography (HPLC), spectrophotometry, electrochemistry, Raman spectroscopy, ion mobility spectrometry, etc. have been used [7-13]. Even though these methods have some advantages, they have some common drawbacks like sophisticated instrumentation, cumbersome pre-treatment of samples, interference from other samples, high operational cost, portability issues, etc. However, compared to these analytical 
methods, fluorescence sensing methods are found to be very promising because of its high sensitivity, selectivity, simplicity and fast response [1-6].

Fluorescence quenching is a process, in which electronic excitation energy of an excited fluorophore is transferred to a non-fluorescent quencher molecule via several mechanisms such as energy transfer, charge transfer, molecular re-arrangement, excited state reactions, diffusion, ground state complex formation, etc. and the fluorescence intensity of the fluorophore decreases. This energy transfer can be explained either by dynamic (collisional) or static quenching mechanisms. However, there must be an interaction between the fluorophore and quencher, no matter what kind of quenching mechanism takes place [14-15]. The fluorescence quenching of organic molecules by various quenchers like aromatic amines, bromobenzene, carbon tetrachloride, metal ions, halide ions, etc. are mainly used to understand the nature of molecular interactions in various systems. Further, from quenching studies, one can reveal the diffusion rate of quenchers, localization of fluorophores in proteins and membranes and their accessibility to quenchers. The quenching studies are also very important in biological, chemical and medical sciences [16-17].

D. Sriramulu et.al have reported on perylene derivatives viz. perylene diimide and perylene monomide as fluorescent probes for the detection of common amines in solution by using fluorescent techniques [18]. E. Bozkurt et.al have shown that, novel pyrazoline derivative can be used for aniline detection via fluorescence quenching [15]. Y. Liu et.al have reported that, aniline in an aqueous solution can be degraded by using non thermal plasma generated in microbubbles [19]. X. Li et.al have reported on efficient treatment of aniline containing wastewater in bipolar membrane microbial electrolysis cell- Fenton system [20]. F. Song et.al have synthesised five isomorphic lanthanide metal organic frameworks and reported the selective fluorescence sensing of aniline [21].

In the present study, we have used novel thiophene substituted 1,3,4-oxadiazole derivative TSO as a fluorophore. The 1,3,4-oxadiazole derivatives are the most stable among the oxadiazole isomers and provide better thermal, luminescent, and electron transporting or hole blocking abilities that could play an important role and meet the requirements to construct an efficient sensor for the detection of explosive nitro aromatic compounds. In recent years, 1,3,4oxadiazole derivatives have also attracted researchers due to their vital role in medicinal chemistry, material chemistry, high range of pharmacological and biological activity [22], small-molecule materials [23-25], polymeric materials [26-28], construction of OLEDs, 
optoelectronics, organic photovoltaics, biomedical imaging, fluorescence sensors, metal ions sensing and as donor- $\pi$-acceptor molecules to work as efficient sensitizers in dye-sensitized solar cells [29-31].

The present fluorophore TSO contain electron deficient 1,3,4-oxadiazole as an electron acceptor and electron rich thiophene group as an electron donor. The presence of electron deficient 1,3,4-oxadiazole makes charge transfer possible from the electron rich aromatic amines and subsequently leads to the fluorescence quenching of the fluorophore. The vast applications of 1,3,4-oxadiazole derivatives and the charge transfer abilities motivated us to carry out this research work on the novel fluorophore TSO for the detection of hazardous aromatic amines through fluorescence quenching mechanisms and to the best of the authors' knowledge, this is the first report on this novel fluorophore in this regard.

\section{Experimental}

\subsection{Materials}

The novel thiophene substituted 1,3,4-oxadiazole derivative TSO is synthesized and the details are given in the earlier publication [32]. For the study of fluorescence quenching mechanism of fluorophore TSO using aromatic amines namely, 2,4-dimethylaniline(2,4DMLA), 3-chloroaniline(3-CRA), 4-chloroaniline(4-CRA), o-anisidine(o-ANS), and mtoluidine(m-TLD) and as well as the ethanol solvent was of the spectroscopic grade obtained from Spectrochem Pvt. Ltd. Mumbai, India. The amines are used as quenchers and they were double distilled before use and solvent were used without further purification to prepare the solutions. The stock solution of the fluorophore was kept at a $10^{-5} \mathrm{M}$ concentration to avoid the self-quenching process. The quencher concentration is varied from $1 \mathrm{mM}$ to $10 \mathrm{mM}$ in all the cases and all the measurements were done at room temperature.

The molecular structures of fluorophore TSO and the aromatic amines are shown in Fig.1 and Fig.S1. 


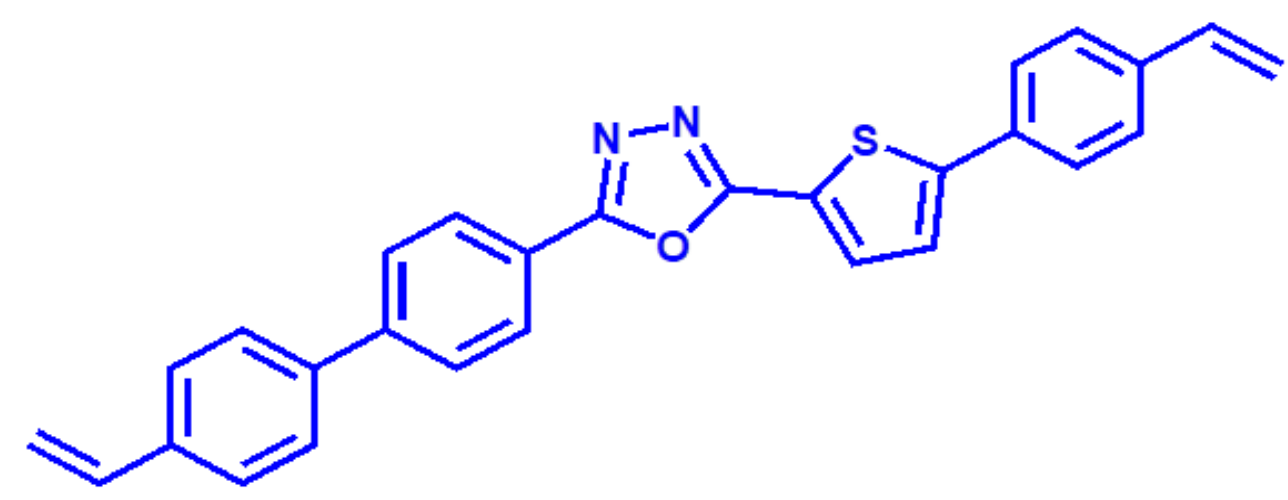

Fig.1 Molecular structure of thiophene substituted 1,3,4-oxadiazole derivative TSO

\subsection{Apparatus}

The UV-Visible absorption and fluorescence spectra were recorded using Carry-300 UV-Visible absorption spectrophotometer and Hitachi F-7000 spectrofluorometer respectively. The fluorescence lifetime measurements were carried out with an ISS Chronos$\mathrm{BH}$, time-correlated single-photon counting (TCSPC) spectrometer with a $340 \mathrm{~nm}$ pulsed diode laser operating at $8 \mathrm{MHz}$ frequency. The samples were excited at 330nmwavelength. The fluorescence decay curves are analysed using lifetime distribution Vinci multidimensional software and the lifetime data was analysed by a double fit exponential function with $\chi^{2}$ value close to unity. The reduction potential of TSO was measured using Cyclic Voltammetry (CV) using an electrochemical Analyzer/Work station (model: CHI112C, series, USA) at $0.1 \mathrm{M}$ tetrabutyl ammonium hexafluorophosphate (TBAPF6) as a supporting electrolyte with a scan rate of $1 \times 10^{-3} \mathrm{Vs}^{-1}$. The theoretical calculations have been performed using the Density Functional Theory (DFT) using the Gaussian 09W program with B3LYP/6.11++G(d,p) level theory.

\section{Results and discussion}

\subsection{Steady-state absorption and fluorescence studies}

The absorption and fluorescence spectra of TSO were recorded in ethanol and are given in Fig.S2. The wavelength corresponding to the absorption maxima of TSO in ethanol was found to be at $330 \mathrm{~nm}$. The fluorescence intensities were measured by exciting the fluorophore TSO at $330 \mathrm{~nm}$ and the maximum fluorescence intensity observed at wavelength $400 \mathrm{~nm}$.

The absorption spectra of TSO were recorded with varying concentrations (1mM-10mM) of aromatic amines in ethanol and are as shown in the Fig.S3. It is observed that the 
absorption spectra of TSO show an increase the absorbance with increasing in the quencher concentration and without any shift in the absorption maxima of the fluorophore in the presence of aromatic amines. This shows that there is no formation of the ground state complex.

The fluorescence spectra of TSO $\left(10^{-5} \mathrm{M}\right)$ in the absence and the presence of the aromatic amines (1mM-10mM) were recorded in ethanol and are shown in Fig.2. It is observed that, as the concentration of aromatic amines increases, an appreciable quenching is observed in the fluorescence intensity of TSO fluorophore without any change in the shape and position of the fluorescence spectra. This indicates the significant molecular interactions under the present experimental conditions.
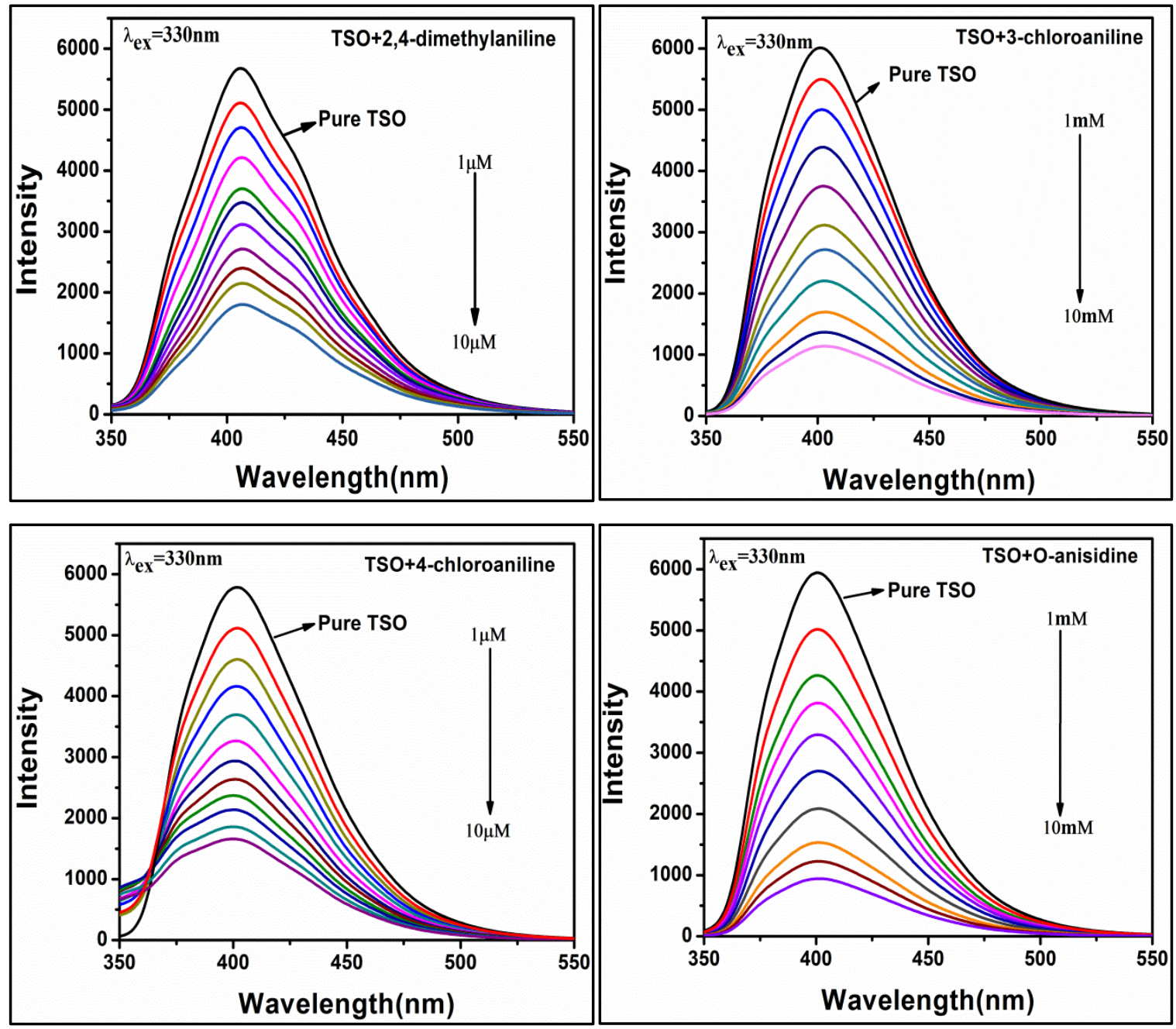


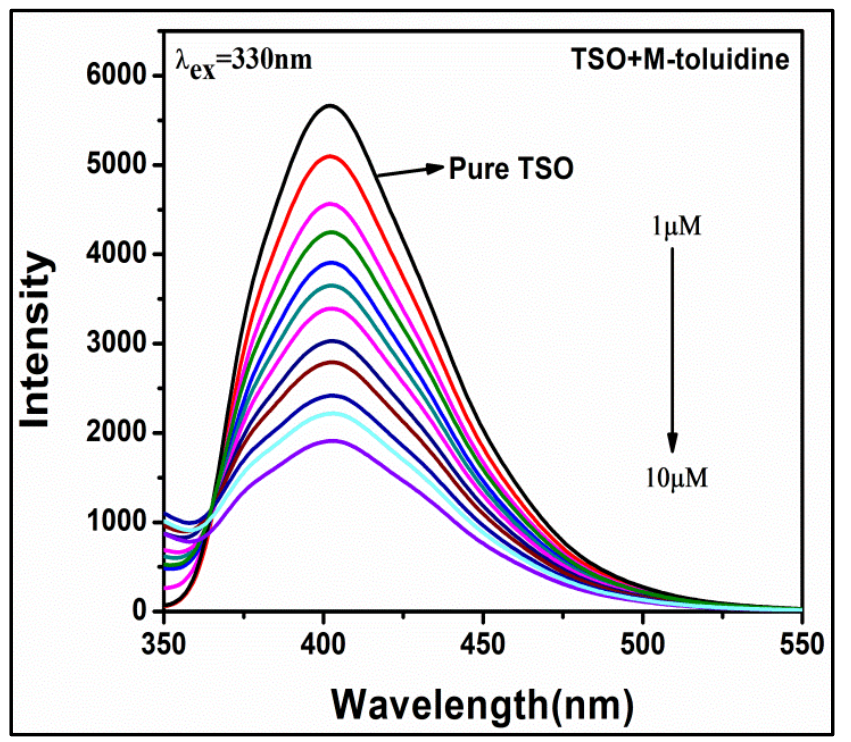

Fig.2 Fluorescence spectra of fluorophore TSO with increasing concentration of aromatic amines

Further, the steady state Stern-Volmer (S-V) equation is used to verify the type of fluorescence quenching mechanism involving the fluorophore and quencher. The SternVolmer (S-V) equation for the steady-state method is given in Eq. (1)[33-34].

$\frac{\mathrm{I}_{0}}{\mathrm{I}}=1+\mathrm{k}_{\mathrm{SV}}[\mathrm{Q}]$

Where $\mathrm{I}_{0}$ and I are the fluorescence intensities of the fluorophore in the absence and presence of quencher, [Q] is quencher concentration and $\mathrm{ksV}$ is the $\mathrm{S}-\mathrm{V}$ constant and is defined as follows

$\mathrm{k}_{\mathrm{SV}}=\mathrm{k}_{\mathrm{q}} \tau_{0}$

Where, $\mathrm{k}_{\mathrm{q}}$ is the bimolecular quenching rate parameter and $\tau_{0}$ is fluorescence lifetime of the fluorophore in the absence of quencher.

In many cases, the Stern-Volmer plots $\left(\left(\mathrm{I}_{0} / \mathrm{I}\right)\right.$ versus $\left.[\mathrm{Q}]\right)$ were found to be linear, in which the quenching mechanism is primarily due to the dynamic process, where the diffusion process is the dominant one [34]. But in our studies, we observed that the S-V plots for all the aromatic amines are found to be nonlinear and show an upward positive deviation at higher concentrations. Similar results were also obtained by others [35-36] and the typical SV plot with all aromatic amines is shown in Fig.3. 


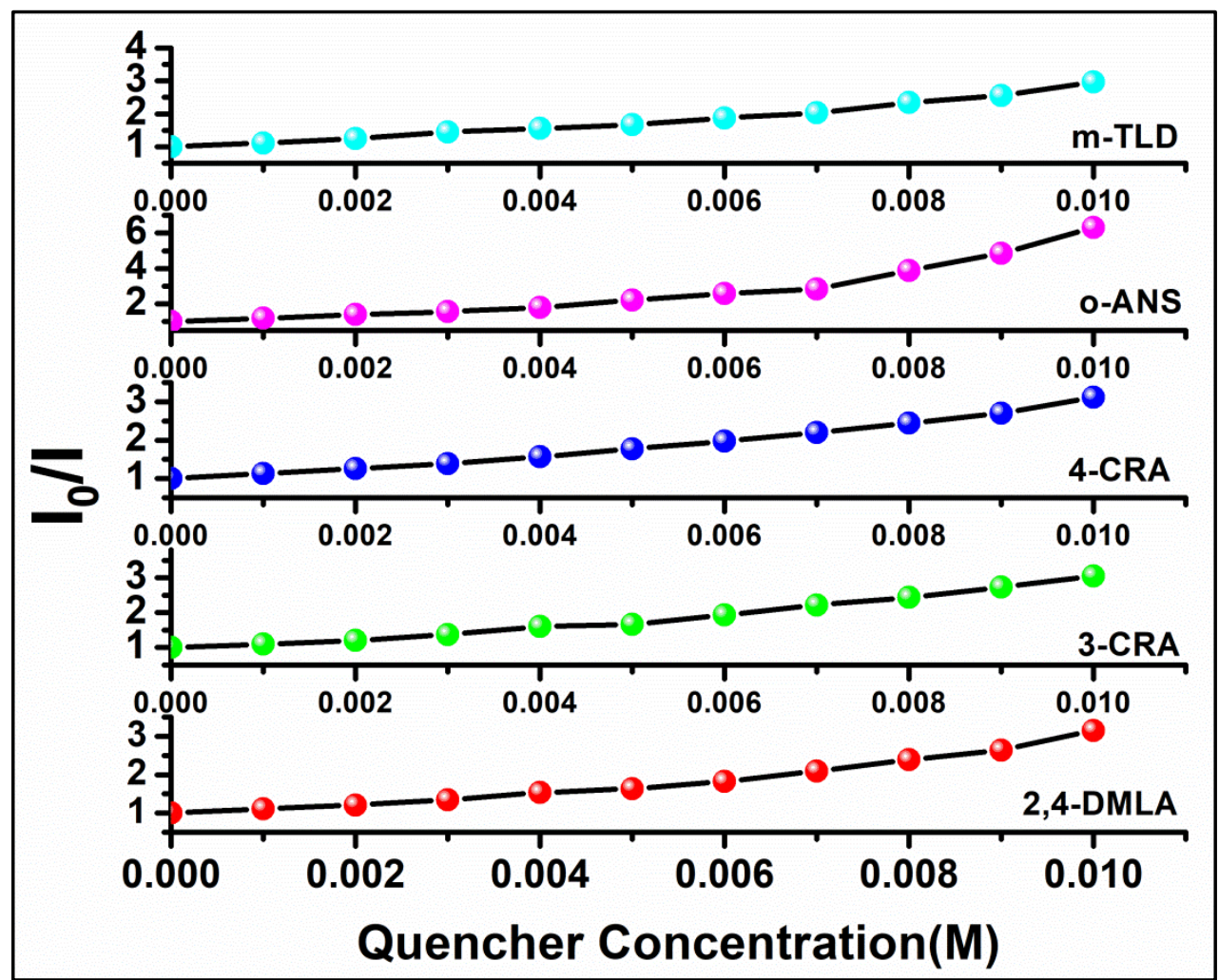

Fig.3 Steady-state Stern-Volmer plot for TSO

The positive deviation in the steady-state $\mathrm{S}-\mathrm{V}$ plots suggests that, the quenching mechanism is not purely dynamic (collisional quenching), which may be due to the formation of either ground-state complex or the static quenching process [36].

\subsection{Ground-state complex formation model}

The possibility of the ground-state complex formation has been analysed by using modified the $\mathrm{S}-\mathrm{V}$ equation $[35,36]$ and is given in Eq.(3).

$\frac{\left[\left(I_{0} / I\right)-1\right]}{[\mathrm{Q}]}=\left(k_{S V}+k_{g}\right)+k_{S V} k_{g}[\mathrm{Q}]$

Where, $\mathrm{k}_{\mathrm{SV}}$ and $\mathrm{kg}_{\mathrm{g}}$ are the Stern-Volmer constant and the ground-state association constant respectively.

According to Eq.(3), the plots $\left[\left(\mathrm{I}_{0} / \mathrm{I}\right)-1\right] /[\mathrm{Q}]$ vs.[Q] for TSO were made and are shown in Fig.4. All the plots are found to be linear. From the knowledge of intercept and slope through the least square fit method, the values of $\mathrm{ksv}_{\mathrm{S}}$ and $\mathrm{kg}_{\mathrm{g}}$ are calculated and are found to be imaginary for all the quenchers studied. These experimental findings ruled out the possibility of ground-state complex formation. Thus, these results are in agreement with the absorption studies. 


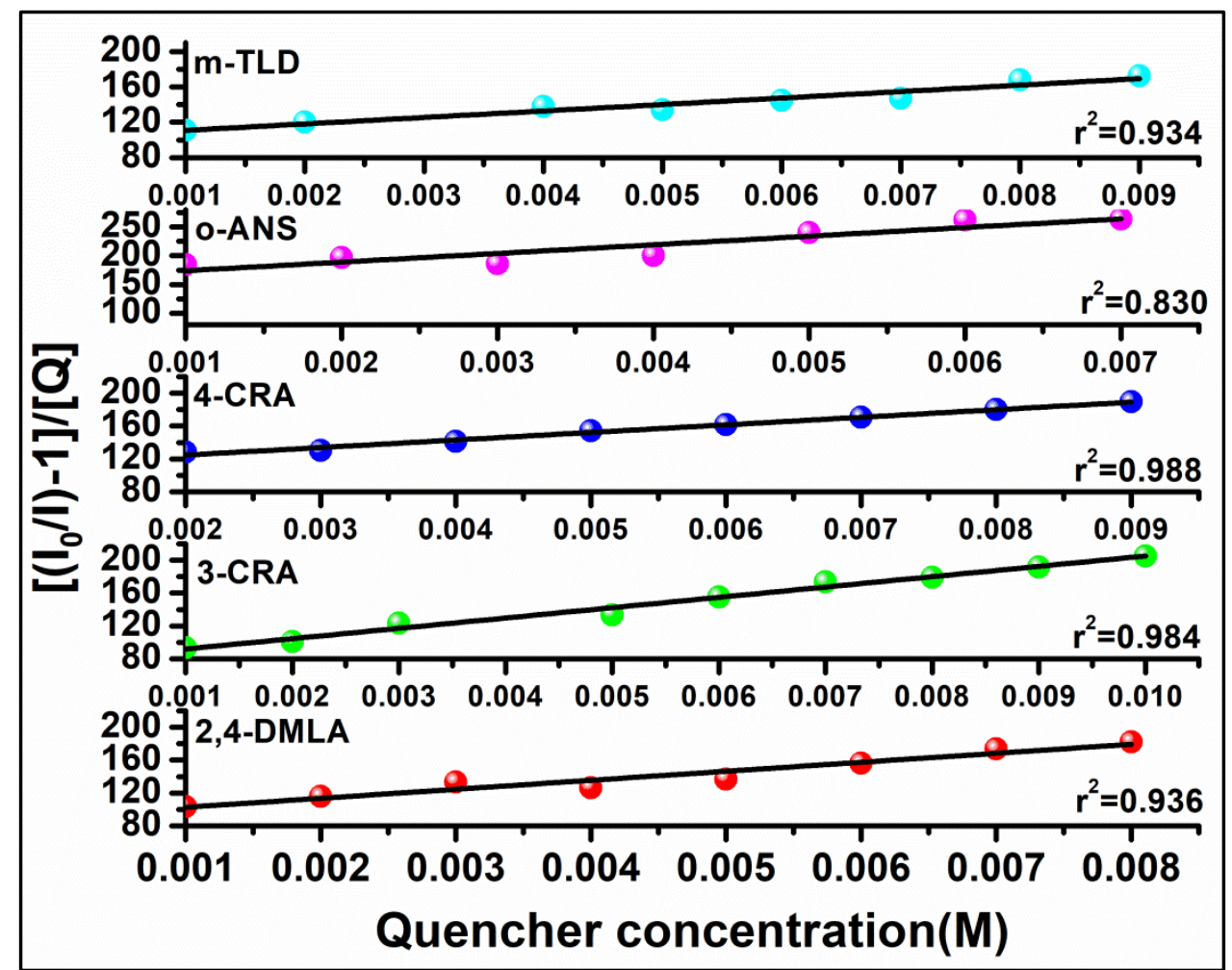

Fig.4 Modified S-V plots [(I $/ \mathrm{I})-1] /[\mathrm{Q}]$ against [Q] for TSO according to ground-state complex formation model.

\subsection{Sphere of action static quenching model}

To establish the static quenching phenomenon in the excited state, the sphere of action static quenching model is invoked as suggested by Frank and Wawilow [37]. According to this model, instantaneous or static quenching occurs if the quencher molecule is very close or in contact with the fluorescent molecule at the moment of its excitation. It can be explained by the fact that only a certain fraction ' $\mathrm{W}$ ' of the excited state is quenched by the collisional mechanism. The fraction of the fluorophore molecules in the excited state which is $(1-W)$, are de-activated almost instantaneously after being formed because a quencher molecule happens to be randomly positioned in the closeness at the time the molecules are excited and interacts very strongly with them. In addition to this model, several other methods were also used (Smoluchowski model, etc.) to describe the static quenching process, all leading to the modified form of following $\mathrm{S}-\mathrm{V}$ equation as given in Eq. 4 [38-40].

$\frac{I_{0}}{I}=\frac{1+K_{S V}[\mathrm{Q}]}{W}$

(4) 
Here, $\mathrm{W}$ is a fraction of fluorophore quenched due to the collision in the excited state and it depends on the quencher concentration [Q]. All other terms have their usual meaning. In order to study the non-linearity in the S-V plot, Eq. (4) is modified as follows.

$\frac{\left[1-\frac{I}{I_{0}}\right]}{Q}=k_{S V}\left[\frac{I}{I_{0}}\right]+\frac{(1-W)}{[Q]}$

According to Eq. (5), the plots of $1-\left(\mathrm{I}_{0} \mathrm{I}_{0}\right) /[\mathrm{Q}]$ against $\mathrm{I} / \mathrm{I}_{0}$ were made and are found to be linear as shown in Fig.5.

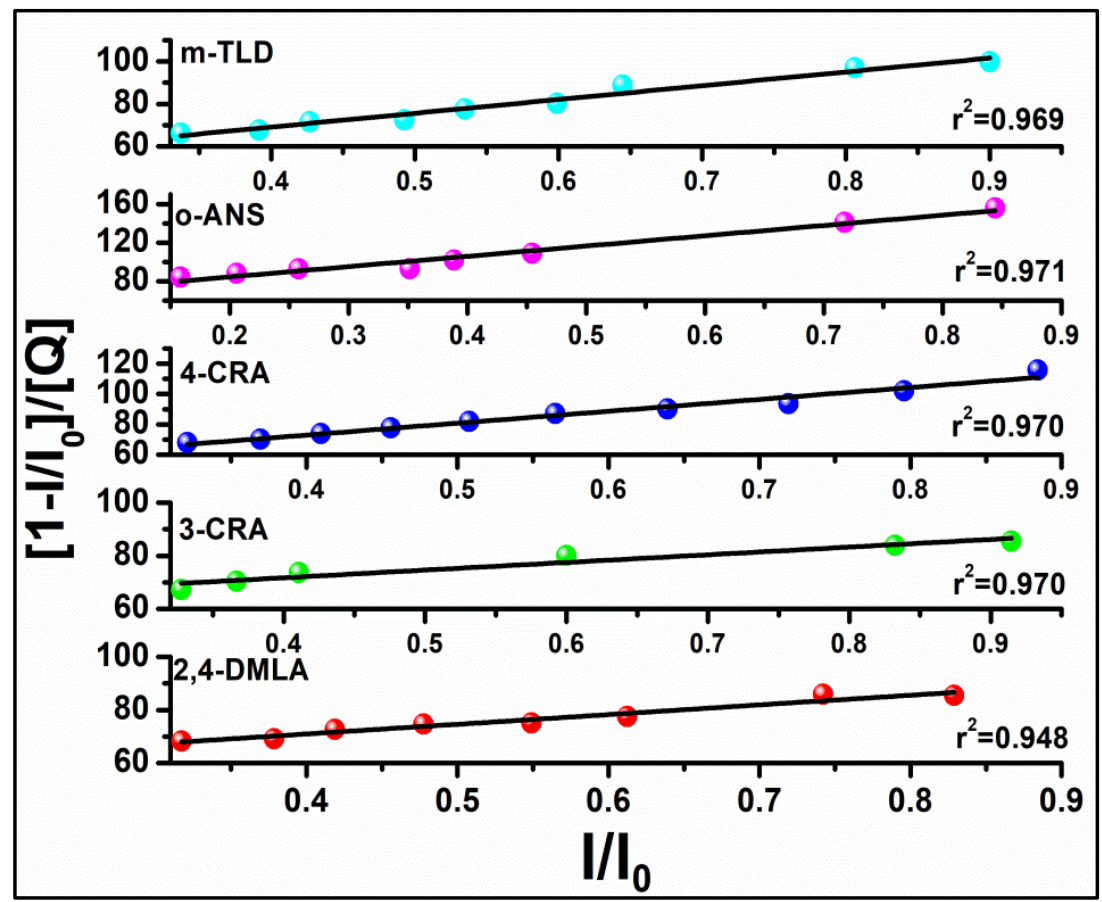

Fig.5 Modified S-V plots[ [1-(I/I $\left.\left.\mathrm{I}_{0}\right)\right] /[\mathrm{Q}]$ against $\left.\mathrm{I} / \mathrm{I}_{0}\right]$ for TSO according to sphere of action static quenching model

The linearity in the modified S-V plot leads to the calculation of the Stern-Volmer constant $\left(k_{S V}\right)$. Further, the bimolecular quenching rate parameter $k_{q}\left(=\mathrm{k}_{S v} / \tau_{0}\right)$ is determined using the Stern-Volmer constant and are given in Table-1. It is observed that, the values of the SternVolmer constants are in the same range as the already reported values [35, 36, 38]. The larger magnitude of the Stern-Volmer constant (ksv) represents the strong quenching interaction between the fluorophore and aromatic amines. From Table-1, the Stern-Volmer constant $\left(\mathrm{k}_{\mathrm{SV}}\right)$ values for o-ANS is large as compared to remaining aromatic amines, this may be due to the strong electron-donating group present in the o-ANS. 
Table-1 The values of steady-state S-V constant $\left(k_{S V}\right)$, the quenching rate parameter $\left(k_{q}\right)$, intercept $[(1-\mathrm{W}) / \mathrm{Q}]$, range of $\mathrm{W}$, static quenching constant $(\mathrm{V})$, and radius of the sphere of action $r$ for quencher

\begin{tabular}{cccccccc}
\hline Quencher & $\begin{array}{c}\mathbf{k s v} \\
\left(\mathbf{M}^{-1}\right)\end{array}$ & $\begin{array}{c}\mathbf{k}_{\mathbf{q}} \times \mathbf{1 0}^{\mathbf{1 0}} \\
\left(\mathbf{M}^{-1} \mathbf{s}^{-\mathbf{1}}\right)\end{array}$ & $\begin{array}{c}\text { Intercept } \\
\mathbf{I}\end{array}$ & $\begin{array}{c}\text { Range of } \\
\mathbf{W}\end{array}$ & $\begin{array}{c}\mathbf{V} \mathbf{m o l}^{-\mathbf{1}} \\
\mathbf{d m}^{\mathbf{3}}\end{array}$ & $\mathbf{r}$ inA & $\begin{array}{c}\mathbf{R} \text { in } \\
\mathbf{A}^{\mathbf{0}}\end{array}$ \\
\hline 2,4-DMLA & 36.592 & 4.194 & 56.303 & $0.437-0.944$ & 68.581 & 30.066 & 7.659 \\
3-CRA & 26.945 & 3.065 & 60.129 & $0.399-0.940$ & 74.594 & 30.121 & 7.491 \\
4-CRA & 78.618 & 8.944 & 41.463 & $0.583-0.959$ & 41.427 & 26.588 & 7.491 \\
0-ANS & 106.78 & 12.147 & 63.761 & $0.362-0.936$ & 78.240 & 31.415 & 7.615 \\
m-TLD & 65.046 & 7.400 & 43.066 & $0.569-0.967$ & 49.571 & 27.983 & 7.475 \\
\hline
\end{tabular}

To support static and dynamic(collisional) quenching in the excited state, the magnitudes of the static quenching constant $(\mathrm{V})$ and radii of the sphere of action or kinetic distance(r) were determined according to the Eqs.(6) and (7).

$W=e^{-V[Q]} \quad$ or $\ln (1 / W)=V[Q]$

$\frac{V}{N^{\prime}}=\frac{4}{3} \pi \mathrm{r}^{3}$

Where $N^{\prime}$ is Avogadro's number per millimole.

The values of $\mathrm{V}$ and $\mathrm{r}$ are given in Table-1. The values of $\mathrm{V}$ and $\mathrm{r}$ are found to be in the same range as reported by others $[39,40]$. From the Table-1, it is observed that the $\mathrm{k}_{\mathrm{SV}}$ values are larger relative to the values of $\mathrm{V}$ for 4-CRA, o-ANS, and $\mathrm{m}-\mathrm{TLD}$, indicating the higher contributions of dynamic processes in the overall quenching mechanism [39].

The radii of the fluorophore $\left(R_{Y}\right)$ and the quencher $\left(R_{Q}\right)$ molecules were determined by adding the atomic volumes of all the atoms constituting the molecule as suggested by Edward [41] and are given in Table-1. The sum of the molecular radii $R\left(R=R_{Y}+R_{Q}\right)$ is referred to as encounter distance or contact distance or reactive distance. This value of $\mathrm{R}$ is compared with the value of the radius of the sphere of action ' $r$ ' to verify whether the reaction is due to the "static effect" or not. From Table-1, it is observed that the values of kinetic distance ' $r$ ' are greater than the encounter distance $\mathrm{R}$. Therefore, according to Andre et al. [42] and Zeng et al. [43] the static effect takes place in the case of steady-state experiments irrespective of ground-state complex formation, provided that the reactions are diffusion limited. These results reveals that the sphere of action static quenching model valid 
in our case. Further, it may also be noted that a positive deviation inS-V plot is expected when both static and dynamic quenching occurs simultaneously [36].

\subsection{Finite sink approximation model}

To find whether the reactions are diffusion-limited, we invoked the finite sink approximation model [44]. Eq. (8) represents the modified S-V equation according to this model.

$k_{S V}^{-1}=\left(k_{S V}^{O}\right)^{-1}-\frac{\left(2 \pi N^{\prime}\right)^{1 / 3}}{4 \pi N^{\prime} D \tau}[Q]^{1 / 3}$

Here, $k_{S V}^{O}$ is $\mathrm{S}-\mathrm{V}$ constant at $[\mathrm{Q}]=0$ and $\mathrm{D}$ is the mutual diffusion coefficient. $k_{S V}^{-1}$ is determined from the knowledge of $k_{s v}$ for different concentrations of quencher from $1 \mathrm{mM}$ to $10 \mathrm{mM}$ and is given by,

$k_{S V}=\left[\left(\frac{I_{0}}{I}\right)-1\right] /[Q]$

For efficient quenching processes (concentration-dependent), the value of $k_{s v}$ is often observed to increase with quencher concentration [Q]. Hence, the values of $k_{s v}$ were determined at each quencher concentration.

According to Eq. (8), the plots of $k_{S V}^{-1}$ against $[Q]^{1 / 3}$ were made and are shown in Fig.6. The plots are found to be linear with a negative slope.

The mutual diffusion coefficient $\mathrm{D}$ can be obtained from the slope of the plot $k_{S V}^{-1}$ against $[Q]^{1 / 3}$ and from the known values of $\mathrm{N}^{\prime}$ and $\tau_{0}$. From the intercept, $k_{S V}^{O}$ is determined. Further, using the values of mutual diffusion coefficient $\mathrm{D}$ and $k_{S V}^{O}$, the distance parameter $\mathrm{R}^{\prime}$ is calculated for all quenchers using Eq.(10) and these values are given in Table-2. 


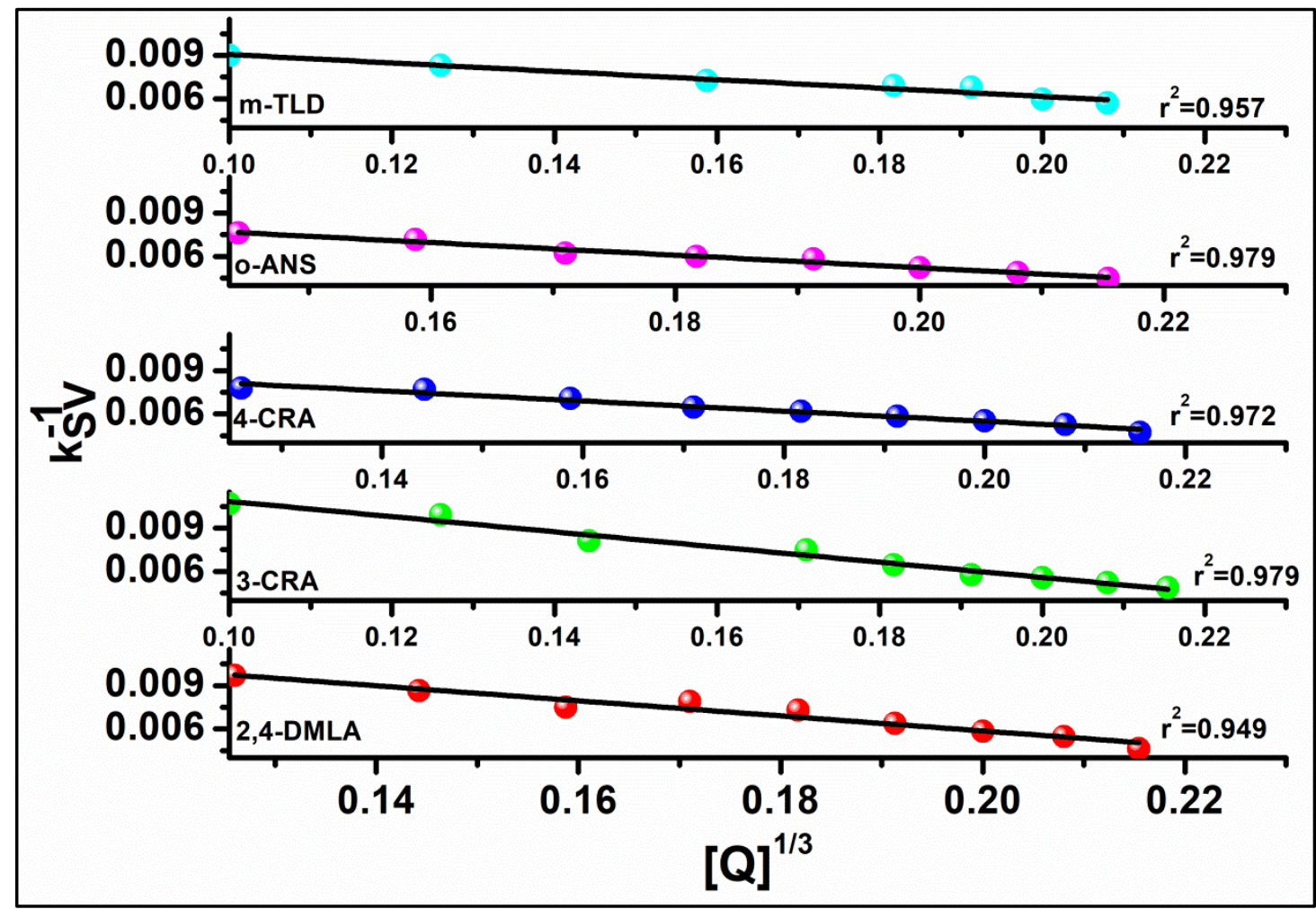

Fig.6 Modified S-V plots $\left[K_{S V}^{-1}\right.$ vs. $\left.[Q]^{1 / 3}\right]$ for TSO according to Finite sinks approximation model

$k_{S V}^{O}=4 \pi N^{\prime} R^{\prime} D \tau_{0}$

In order to confirm the bimolecular reactions to be diffusion-limited, we have compared the values of distance parameter $\mathrm{R}^{\prime}$ and the encounter distance $\mathrm{R}$. The bimolecular fluorescence quenching reactions are said to be diffusion limited, if the $\mathrm{R}^{\prime}>\mathrm{R}$. From the Table-2 it is observed that $\mathrm{R}^{\prime}>\mathrm{R}$ in all the cases. Hence it may be concluded that the bimolecular reactions are diffusion limited.

Further, the diffusion-controlled rate parameter $\left(k_{d}\right)$ is determined using Eq.(11) and is presented in Table-2.

$k_{d}=4 \pi N^{\prime} R^{\prime} D$

According to Joshi et al [45], the bimolecular reactions are said to be diffusion-limited, if the value of the bimolecular quenching rate parameter $\left(\mathrm{k}_{\mathrm{q}}\right)$ (determined from a modified form of the Stern-Volmer equation (5)) is greater than the $k_{d}$. From Table-2, the value of $\mathrm{k}_{\mathrm{q}}$ is greater than $k_{d}$ only for o-ANS suggesting that diffusion-limited reactions take place in o-ANS with TSO. But for the remaining quenchers, the values of $\mathrm{k}_{\mathrm{q}}$ are less than $k_{d}$. This may be due to the reduced values of the diffusion coefficient. Hence, we may infer that diffusion assisted 
static quenching is responsible for fluorescence quenching in the case of 2,4-DMLA, 3CRA, 4-CRA, and m-TLD.

Table-2 The values of $k_{S V}^{O}$ (steady-state quenching constant at [Q]=0), mutual diffusion coefficient $\mathrm{D}$ (finite sink model), distance parameter $R^{\prime}, 4 \pi N^{\prime} R^{\prime} D$, the quenching rate parameter $k_{q}$ and activation energy-controlled rate constant $k_{a}$

\begin{tabular}{cccccc}
\hline Quencher & $\boldsymbol{k}_{\boldsymbol{S} V}^{\mathbf{0}} \mathbf{M}^{\mathbf{- 1}}$ & $\begin{array}{c}\mathbf{D} \times \mathbf{1 0}^{-\mathbf{5}} \\
\mathbf{c m}^{\mathbf{2}} \mathbf{s}^{\mathbf{1}}\end{array}$ & $\mathbf{R}^{\mathbf{i n}} \mathbf{A}^{\mathbf{0}}$ & $\begin{array}{c}\mathbf{k}_{\mathbf{q}} \times \mathbf{1 0}^{\mathbf{1 0}} \\
\left(\mathbf{M}^{\mathbf{- 1}} \mathbf{s}^{\mathbf{- 1}}\right)\end{array}$ & $\begin{array}{c}\mathbf{k}_{\mathbf{d}} \times \mathbf{1 0}^{\mathbf{1 0}} \\
\left(\mathbf{M}^{-\mathbf{1}} \mathbf{s}^{\mathbf{- 1}}\right)\end{array}$ \\
\hline 2,4-DMLA & 61.350 & 4.478 & 20.590 & 4.194 & 6.979 \\
3-CRA & 62.112 & 4.453 & 20.963 & 3.065 & 7.066 \\
4-CRA & 80.000 & 6.694 & 17.961 & 8.944 & 9.101 \\
0-ANS & 78.740 & 4.770 & 24.809 & 12.147 & 8.957 \\
m-TLD & 81.766 & 7.574 & 16.225 & 7.400 & 9.302 \\
\hline
\end{tabular}

\subsection{Time resolved fluorescence studies}

The steady-state method results reveal that fluorescence quenching is due to the static effect and diffusion limited. In order to verify these results, we have carried out fluorescence quenching experiments through time-resolved fluorescence with varying concentrations of aromatic amines. As this method is considered to be accurate than the steady-state method, the fluorescence lifetime of TSO with varying concentrations of aromatic amines was measured and the decay profiles are shown in Fig.7. In all the cases, the fluorescence decay profile was fitted bi-exponentially with a residual $\chi^{2}$ value which is nearly equal to one. Fluorescence lifetime values are presented in Table-S1. The dynamic and static fluorescence quenching mechanisms can be distinguished with time-resolved measurements. In the static quenching process, the fluorescence decay lifetime of the fluorophore will remain unchanged as the concentration of the quencher is increased. However, in collisional quenching a decrease in the average fluorescence lifetime of the excited molecule. From Fig.7, it is observed that, with increasing quencher concentration, a decrease in the fluorescence lifetime of the fluorescence dye. This suggests that, the fluorophore is quenched through collisional interactions with the quencher. 

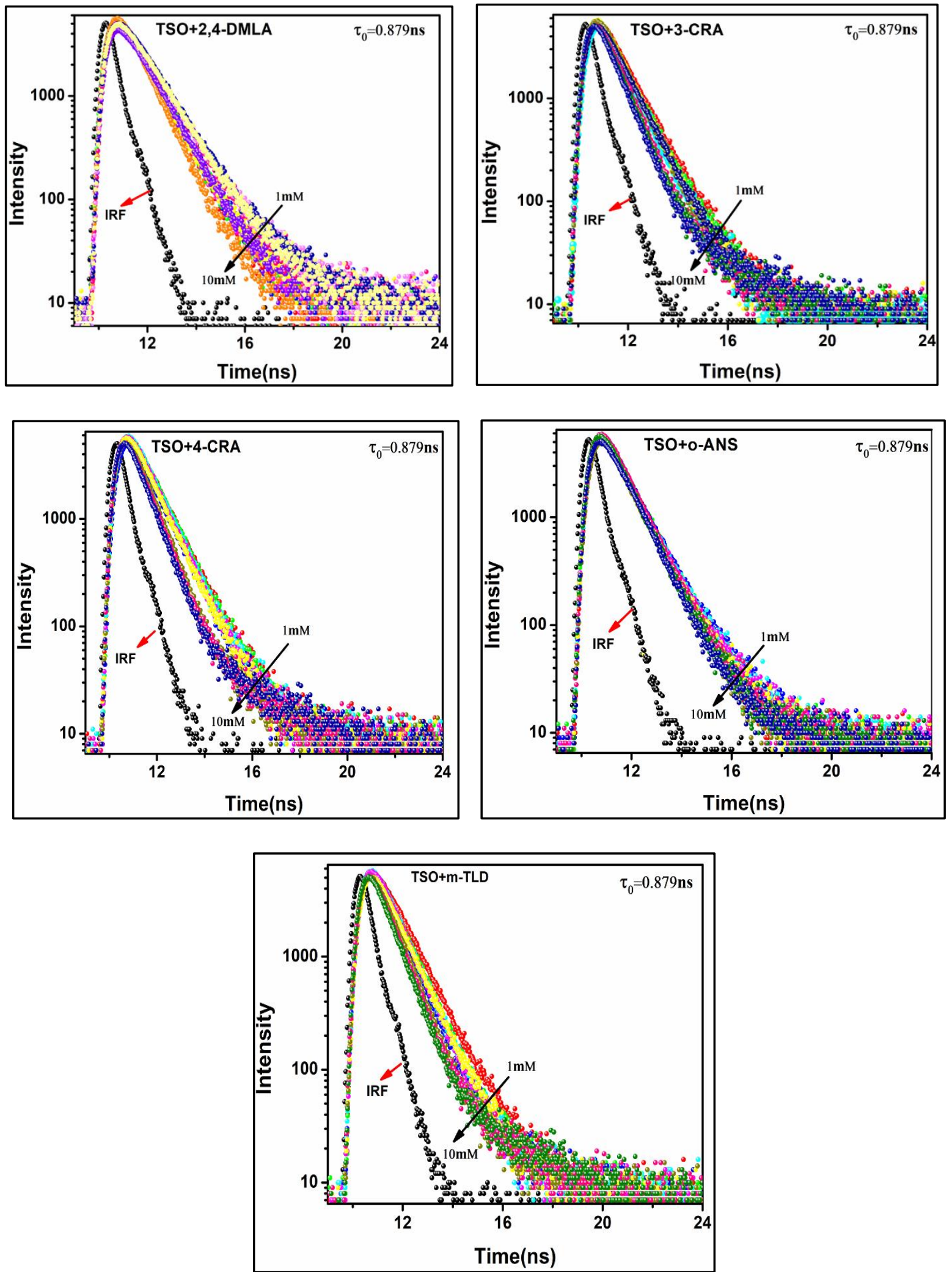

Fig.7 Fluorescence decay profile of fluorophore TSO with increasing concentration of aromatic amines 
The Stern-Volmer (S-V) equation [38-40] for the time-resolved method is given by.

$\frac{\tau_{0}}{\tau}=1+\mathrm{k}_{\mathrm{sv}}^{\prime}[\mathrm{Q}]$

Where, $\tau_{0}$ and $\tau$ are the fluorescence lifetime of fluorophore in the absence and presence of the quencher, respectively. [Q] is quencher concentration and $k_{s v}^{\prime}$ is the time resolved S-V constant and is defined as follows.

$k_{s v}^{\prime}=k_{q}^{\prime} \tau_{0}$

Where $k_{q}^{\prime}$ is the bimolecular quenching rate parameter. The time resolved stern-Volmer plot is shown in the Fig.8 and it is observed that time resolved S-V plot shows linearity with increasing concentration of quencher. This result reveals that there is an existence of dynamic quenching between the fluorophore and aromatic amines. Further, from the knowledge of the slope of the S-V plot, the time resolved Stern-Volmer constant and bimolecular quenching constant are calculated and are given in Table-3.

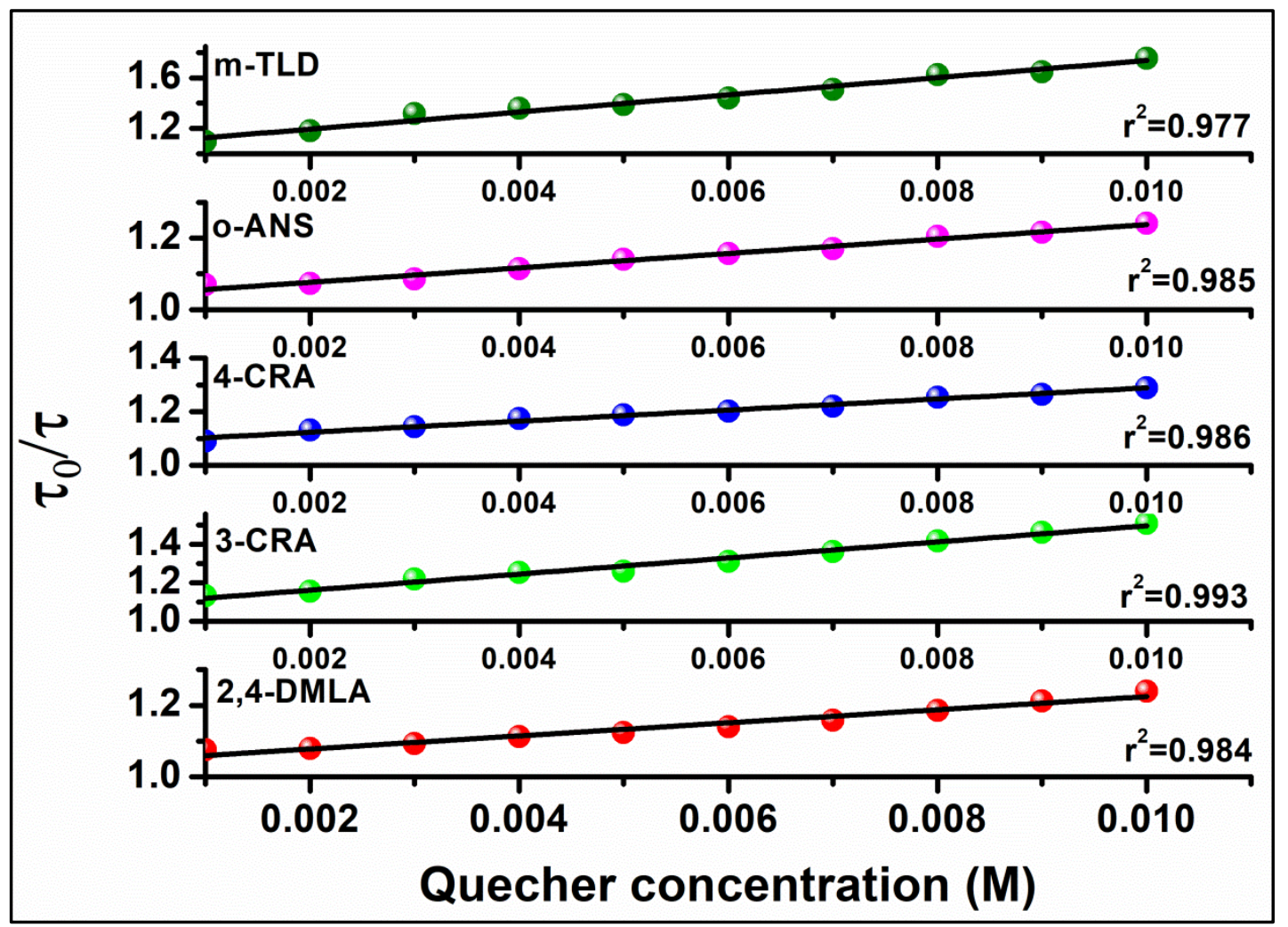

Fig.8 Time-resolved Stern-Volmer plot for TSO molecule and aromatic amines 
Table-3 The values of steady-state $S-V$ constant $\left(k_{S V}^{\prime}\right)$, the quenching rate parameter $\left(k_{q}^{\prime}\right)$ from time resolved method

\begin{tabular}{ccccc}
\hline Quencher & Intercept & $\begin{array}{c}\text { Correlation } \\
\text { coefficient } \\
{ }^{\prime} \mathrm{r}^{2}\end{array}$ & $\begin{array}{c}\text { Slope } \\
\mathrm{ksv} \\
\left(\mathrm{M}^{-1}\right)\end{array}$ & $\begin{array}{c}\text { Bimolecular } \\
\text { quenching constant } \\
\mathrm{k}_{\mathrm{q}} \times 10^{10} \\
\left(\mathrm{M}^{-1} \mathrm{~s}^{-1}\right)\end{array}$ \\
\hline 2,4-DMLA & 1.041 & 0.964 & 18.303 & 2.082 \\
3-CRA & 1.077 & 0.984 & 41.945 & 4.771 \\
4-CRA & 1.082 & 0.986 & 20.712 & 2.556 \\
o-ANS & 1.036 & 0.985 & 20.166 & 2.294 \\
m-TLD & 1.057 & 0.977 & 68.043 & 7.740 \\
\hline
\end{tabular}

From Table-3 it is observed that, the time-resolved S-V constant values are lower than the steady-state S-V constants. Higher values of bimolecular quenching constant suggest the static quenching. Hence, the steady state and time resolved fluorescence methods suggest that, fluorescence quenching is due to static as well as dynamic quenching processes.

\subsection{Cyclic voltammetry (CV) studies}

Further, an analyte is always within the encounter distance with an excited fluorophore and thus electron transfer can occur effectively as a unimolecular process, without involving any diffusion of the reactants. The larger value of quenching efficiency suggests the possibility of electron transfer from aromatic amines to the fluorophore. To understand the reason for the difference in the fluorescence quenching abilities of all analytes, we carried out an electrochemical analysis.

As we know that aromatic amines are the donors of electrons and thiophene substituted 1,3,4-oxadiazole derivatives are electron acceptors. Thus, the oxidation potentials of aromatic amines and reduction potentials of the TSO are essential to understand the electron transfer in the fluorescence quenching mechanisms. Then the possibility of electron transfer from aromatic amines to the fluorophore can be determined by the electrochemical 
analysis [46]. The cyclic voltammogram for the TSO in the presence of supporting electrolyte $\left(\mathrm{TBAPF}_{6}\right)$ in ethanol is shown in Fig.9 and the reduction potential value of TSO is found by the CV graph. The oxidation potential values of aromatic amines (2,4-DMLA, 3CRA, 4-CRA, o-ANS, and m-TLD) were taken from the literature [47]. Oxidation and reduction potentials of amines and TSO are given in Table-4.

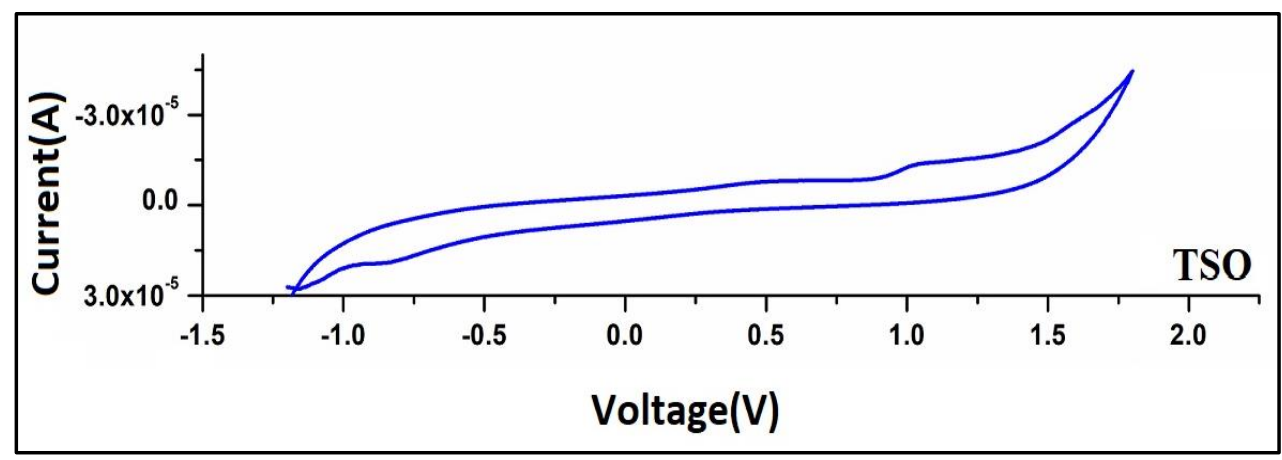

Fig.9 Cyclic Voltammogram of the fluorophore TSO in ethanol solvent.

Table-4 The values of the oxidation potential $\left(E_{1 / 2}^{(o x)}\right)$ of aromatic amines the reduction potential $\left(E_{1 / 2}^{(r e d)}\right)$ TSO, and free energy change for electron transfer $\left(\Delta \mathrm{G}_{\mathrm{et}}\right)$ in ethanol.

\begin{tabular}{cccc}
\hline Quencher & $\boldsymbol{E}_{\mathbf{1} / \mathbf{2}}^{(\text {red })}(\mathbf{e V})$ & $\boldsymbol{E}_{\mathbf{1 / 2}}^{(\boldsymbol{o x})}(\mathbf{e V})$ & $\boldsymbol{\Delta} \mathbf{G}_{\text {et }}(\mathbf{e V})$ \\
\hline 2,4-DMLA & & 0.734 & -2.150 \\
3-CRA & & 0.952 & -1.932 \\
4-CRA & -0.873 & 0.880 & -2.004 \\
o-ANS & & 0.712 & -2.172 \\
m-TLD & & 0.843 & -2.041
\end{tabular}

The possibility of the electron transfer from the excited-state of TSO to the ground-state of the quencher is dependent on the standard free energy change for electron transfer reaction $\Delta \mathrm{G}_{\mathrm{et}}(\mathrm{eV})$. The $\Delta \mathrm{G}_{\mathrm{et}}$ value for an outer-sphere electron-transfer process can be calculated using the Rehm-Weller equation Eq.14 [48].

$\Delta \mathrm{G}_{\mathrm{ex}}=E_{1 / 2}^{(o x)}-E_{1 / 2}^{(\text {red })}-\mathrm{E}^{*}-\frac{\mathrm{e}^{2}}{\varepsilon \mathrm{r}}$

Where $E_{1 / 2}^{(o x)}$ is the ground-state of the oxidation potential of aromatic amines (donor), $E_{1 / 2}^{(r e d)}$ is the reduction potential of TSO (acceptor) is taken from the literature, $\mathrm{E}^{*}$ is the 
singlet excited-state energy of the TSO in the ethanol calculated by the equation $E^{*}=1240 / \lambda$. Where ' $\lambda$ ' is the absorption maxima (330nm) and it is found to be $3.757 \mathrm{eV}$, and $\mathrm{e}^{2} / \varepsilon \mathrm{r}$ is the coulombic energy term, (Here the ' $\mathrm{e}$ ' is the charge of an electron, ' $\varepsilon$ ' is the dielectric constant of the solvent used and $\mathrm{r}$ is the separation between donor and acceptor). In polar solvents such as ethanol, the coulombic term of Eq.(14) is significant concerning the other contributions and can be neglected while finding the $\Delta \mathrm{G}_{\mathrm{et}}$. The calculated values of $\Delta \mathrm{G}_{\mathrm{et}}$ from Eq.(14) for fluorophore and quenchers are presented in Table-4. It is observed that, the higher negative values of $\Delta \mathrm{G}_{\mathrm{et}}$ for the fluorophore with aromatic amines suggests the pronounced thermodynamically favourable electron transfer process from the aromatic amines to the excited-state of TSO.

HOMO and LUMO values of TSO and 2,4-DMLA, 3-CRA, 4-CRA, o-ANS, and mTLD were also calculated theoretically from ab initio computations by using the DFT level of theory using the Gaussian $09 \mathrm{~W}$ program with basis sets $\mathrm{B} 3 \mathrm{LYP} / 6.11++\mathrm{G}(\mathrm{d}, \mathrm{p})$ and are presented in the Table-5. With the knowledge of the HOMO and LUMO values for fluorophore TSO and all the aromatic amines, proposed a schematic energy level diagram for the possible photoinduced electron transfer from aromatic amines to the fluorophore as shown in the Fig.10. It is observed that the LUMO level of all the aromatic amines lies well above the LUMO of the fluorophore and confirms the need for a driving force for electron transfer from aromatic amines into the fluorophore.

Table-5 The HOMO-LUMO and energy gap $(\Delta E)$ of TSO and aromatic amines

\begin{tabular}{cccc}
\hline Molecules & LUMO $(\mathrm{eV})$ & $\mathrm{HOMO}(\mathrm{eV})$ & $\Delta E(\mathrm{eV})$ \\
\hline TSO & -2.462 & -5.906 & 3.444 \\
2,4-DMLA & -0.194 & -5.605 & 4.945 \\
3-CRA & -0.103 & -5.139 & 5.509 \\
4-CRA & -0.161 & -5.480 & 5.319 \\
o-ANS & -0.301 & -5.074 & 4.773 \\
m-TLD & -0.083 & -5.321 & 5.238 \\
\hline
\end{tabular}




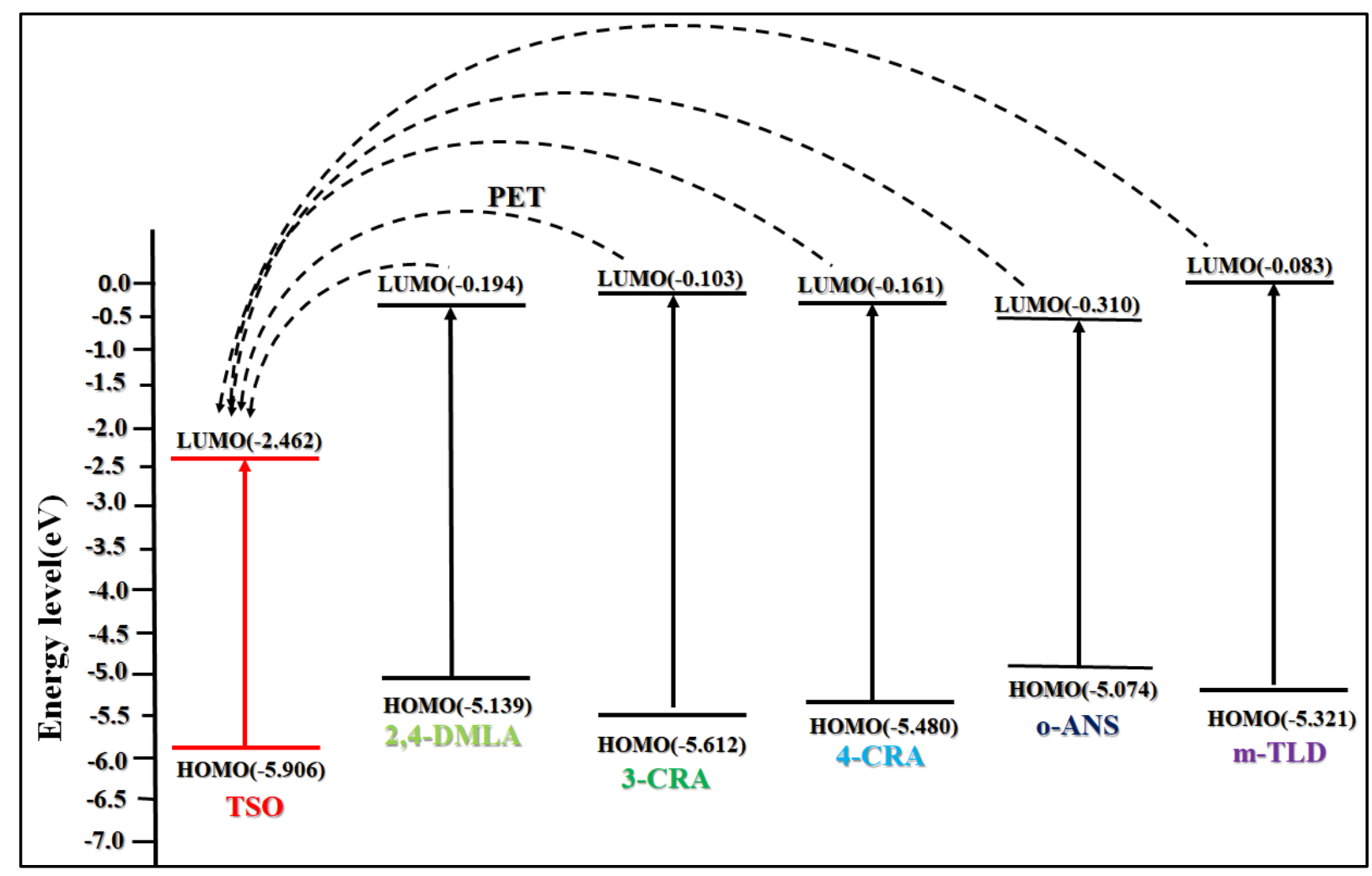

Fig.10 The schematic energy level diagram of photoinduced electron transfer from amines to TSO

\subsection{Analysis of binding equilibria}

In order to estimate the binding constant and to understand the stoichiometry between the fluorophore and quencher, The binding equilibria analysis [49] was carried out according to the Eq.(15) and is given by

$\log \left[\frac{\left(I_{0}-I\right)}{I}\right]=\log K+n \log [Q]$

Where $\mathrm{K}, \mathrm{n}, \mathrm{I}_{0}, \mathrm{I}$, and $[\mathrm{Q}]$ are the binding constant, the number of binding sites, and remaining terms have their usual meaning. According to Eq.15, the plots of $\log \left[\left(\mathrm{I}_{0}-\mathrm{I}\right) / \mathrm{I}\right]$ vs. $\log [\mathrm{Q}]$ for the quenchers 2,4-DMLA, 3-CRA, 4-CRA, o-ANS, and m-TLD in ethanol were made and are shown in Fig.11. These plots showed the best linear fit for all the quenchers. This indicates that there is a 1:1 stoichiometry ratio between the fluorophore and aromatic amines [50]. The values of binding sites (n) and binding constant (K) were estimated from the least-square fit method with the help of slope and intercept and are given in Table-6. The higher values of binding constant (K) confirms the strong binding of the fluorophore with aromatic amines. The ' $\mathrm{K}$ ' values are almost in the same range $\left(10^{2}\right)$ as the previously reported values [34, 37]. 


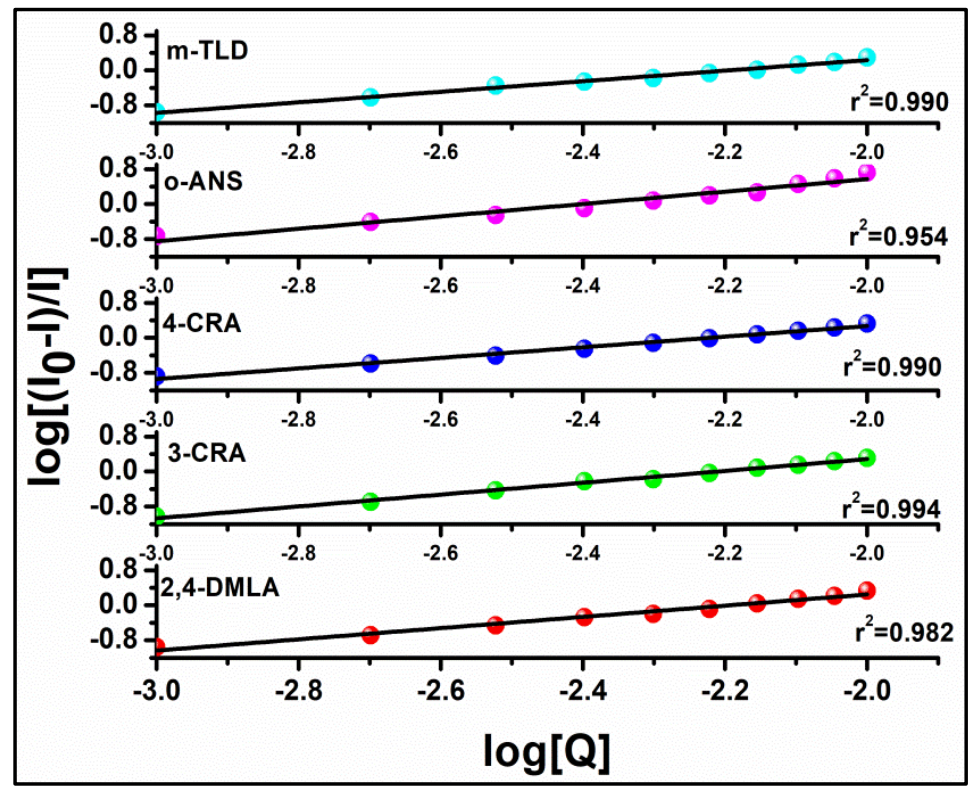

Fig.11 The plots of $\log \left[\left(\mathrm{I}_{0}-\mathrm{I}\right) / \mathrm{I}\right]$ against $\log [\mathrm{Q}]$ for TSO with for the aromatic amines

Table- 6 The values of binding sites $n$ and binding constants $\mathrm{K}$ in ethanol solvent

\begin{tabular}{cccc}
\hline Quencher & $\begin{array}{c}\text { Number of } \\
\text { Binding sites(n) }\end{array}$ & $\begin{array}{c}\text { Binding constant(K) } \\
\mathrm{M}^{-1}\end{array}$ & $\begin{array}{c}\text { Co-relation } \\
\text { coefficient }\end{array}$ \\
\hline 2,4-DMLA & 1.281 & 16.609 & 0.982 \\
3-CRA & 1.351 & 19.846 & 0.994 \\
4-CRA & 1.209 & 14.717 & 0.990 \\
o-ANS & 1.415 & 29.964 & 0.954 \\
m-TLD & 1.204 & 14.083 & 0.990 \\
\hline
\end{tabular}

\section{Conclusion}

The fluorescence quenching of TSO with different environmental pollutant aromatic amine shows the positive deviations in the Stern-Volmer plots with higher values of bimolecular quenching rate parameter. The fluorescence quenching has occurred without involving the ground state complex formation. The kinetic distance ' $r$ ' being greater than ' $R$ ' and the bimolecular quenching rate parameter ' $\mathrm{k}_{\mathrm{q}}$ ' greater than ' $\mathrm{k}_{\mathrm{d}}$ ' indicates that, the quenching reactions are due to static quenching and diffusion-limited. A decrease in the fluorescence lifetime of the fluorescence with increasing quencher concentration confirms the presence of dynamic quenching also. Positive deviation in the S-V plots is due to the combined effect of both dynamic and static quenching processes. The negative free energy change $\left(\Delta \mathrm{G}_{\mathrm{et}}\right)$ indicated that the interaction of TSO with aromatic amines is a spontaneous process or thermodynamically favourable. Analysis of the experimental data using RehmWeller relation and DFT studies confirms that, fluorescence quenching is due to electron 
transfer from amines to the fluorophore. The binding equilibria analysis reveals the 1:1stoichiometric ratio between fluorophore and quencher.

\section{Acknowledgements:}

One of the authors (Thippeswamy. M.S) is thankful to the Principal and Staff, Government First Grade College Harihar-577601 Karnataka, for the continuous support and encouragement. We thank USIC (SAIF), Karnatak University, Dharwad, Karnataka, India for providing the facilities of instruments.

"This research did not receive any specific grant from funding agencies in the public, commercial or not-for-profit sectors".

\section{$\underline{\text { Author Declarations }}$}

Funding - Not applicable

Conflicts of interest - The authors declare that they have no known competing financial interests or personal relationships that could have appeared to influence the work reported in this paper.

Ethics approval/declarations - Not applicable

Consent to participate - Not applicable

Consent for publication - Not applicable

Availability of data and material - Not applicable

Code availability - Not applicable

Authors' contributions -

Thippeswamy M.S: Conceptualization; Data curation; Formal analysis; Investigation; Methodology; Resources; Software; Supervision; Validation; Visualization; Roles/Writing original draft; Writing - review \& editing.

Dr.Lohit Naik: Conceptualization; Data curation; Formal analysis; Investigation; Methodology; Resources; Software; Supervision; Validation; Visualization; Roles/Writing original draft; Writing - review \& editing.

Dr. C. V. Maridevarmath: Roles/Writing - original draft; Writing - review \& editing. 
Dr.G.H.Malimath: Conceptualization; Data curation; Formal analysis; Investigation; Methodology; Resources; Software; Supervision; Validation; Visualization; Roles/Writing original draft; Writing - review \& editing.

\section{References}

1. H.J. Feng, L. Xu, B. Liu, Huan Jiao, Europium Metal-Organic Frameworks as Recyclable and Selective Turn-off Fluorescence Sensors for Aniline Detection, Dalton Trans., 1 (2012) 1-9.

2. T. Gong, P. Li, Q. Sui, J. Chen, J. Xu, E.Q. Gao, Stable electron-deficient metal-organic framework for colorimetric and luminescent sensing of phenols and anilines, J. Mat.Chem. A, 1 (2013) 1-9.

3. X.L. Huang, L. Liu, M.L. Gao, Z. Han, A Luminescent Metal-Organic Framework for Highly Selective Sensing of Nitrobenzene and Aniline, RSC Adv., 1 (2016) 1-5.

4. S. Karthikeyan, V.K. Gupta, R. Boopathy, A. Titus, G. Sekaran, A new approach for the degradation of high concentration of aromatic amine by heterocatalytic Fenton oxidation: Kinetic and spectroscopic studies, J.Mol. Liq., 173 (2012) 153-163.

5. H. Peng, L. Ding, T. Liu, X. Chen, L. Li, S. Yin, Y. Fang, An Ultrasensitive Fluorescent Sensing Nanofilm for Organic Amines Based on Cholesterol-Modified Perylene Bisimide, Chem. Asian J., 7 (2012) 1576-1582.

6. A. Sandeep, V.K. Praveen, K.K. Kartha, V. Karunakaran, A. Ajayaghosh, Supercoiled fibres of self-sorted donor-acceptor stacks: a turn-off/turn-on platform for sensing volatile aromatic compounds, Chem. Sci., 7 (2016) 4460-4467.

7. Z. Guo, X. Song, H. Lei, H. Wang, S. Su, H. Xu, G. Qian, H. Zhang, B. Chen, A ketone functionalized luminescent terbium metal-organic framework for sensing of small molecules, Chem. Commun., 51 (2015) 376-379.

8. Y. Kosaki, H. Izawa, S. Ishihara, K. Kawakami, M. Sumita, Y. Tateyama, Q. Ji, V. Krishnan, S. Hishita, Y. Yamauchi, J.P. Hill, A. Vinu, S. Shiratori, K. Ariga, Nanoporous carbon sensor with cage-in-fiber structure: highly selective aniline adsorbent toward cancer risk management, ACS appl mater inter, 5 (2013) 2930-2934.

9. S.H. Lu, R. Pang, J.M. Fang, Fluorescent sensing of Guanine and Guanosone monophosphste with conjugate receptors incorporating aniline and nappthyridine moieties, Org. Lett. 18 (2016) 1724-1727. 
10. J. Fan, X. Chang, M. He, C. Shang, G. Wang, S. Yin, H. Peng, Y. Fang, FunctionalityOriented Derivatization of Naphthalene Diimide: A Molecular Gel Strategy-Based Fluorescent Film for Aniline Vapor Detection, ACS appl mater inter, 8 (2016) 1858418592.

11. W. Lin, S. Sun, C. Wu, P. Xu, Z. Ye, S. Zhuang, Effects of toxic organic flotation reagent (aniline aerofloat) on an A/O submerged membrane bioreactor (sMBR): Microbial community dynamics and performance, Ecotox.environ. safe, 142 (2017) 14-21.

12. S. Norzaee, B. Djahed, R. Khaksefidi, F.K. Mostafapour, Photocatalytic degradation of aniline in water using $\mathrm{CuO}$ nanoparticles, J. Water Supply Res. T., 66 (2017) 178-185.

13. Y. Xiao, Q. Yang, D. Liu, C. Zhong, Computational design of metal-organic frameworks for aniline recovery from aqueous solution, CrystEngComm, 15 (2013) 9588.

14. L. Naik, I.A.M. Khazi, G.H. Malimath, Turn-off fluorescence studies of novel thiophene substituted 1,3,4-oxadiazoles for aniline sensing, Sens. \& Actu. A. Phys. (2018), https://doi.org/10.1016/j.sna.2018.10.018

15. E. Bozkurta, H.I. Gul, Fluorescence quenching of novel pyrazoline derivative with aniline in different solvents, J.Photochem. \& Photobio. A-Chem. 383 (2019) 111996-1111002.

16. B.G. Evale, S.M. Hanagodimath, Static and dynamic quenching of biologically active coumarin derivative by aniline in benzene-acetonitrile mixtures, J. Lumin., 130 (2010) $1330-1337$.

17. H.S. Geethanjali, D. Nagaraja, R.M. Melavanki, Exploring the mechanism of fluorescence quenching in two biologically active boronic acid derivatives using Stern-Volmer kinetics, J. Lumin., 209 (2015) 669-675.

18. D. Sriramulu, S. Valiyaveettil, Perylene derivatives as a fluorescent probe for sensing of amines in solution, Dyes \& Pigm., 134 (2016) 306-314.

19. Y. Liu, H. Zhang, J. Sun, J. Liu, X. Shen, J. Zhan, A. Zhang, S. Ognier, S. Cavadias, P. Li, Degradation of aniline in aqueous solution using non-thermal plasma generated in microbubbles, Chem. Eng. J. (2018), DOI: https://doi.org/10.1016/j.cej.2018.01.057.

20. X. Li, X. Jin, N. Zhao, I. Angelidaki, Y. Zhang, Efficient treatment of aniline containing wastewater in bipolar membrane microbial electrolysis cell-Fenton system, Water Res., (2017), DOI: 10.1016/j.watres.2017.04.047.

21. J.F. Song, H.F. Wen, J.J. Luo, Y.Y. Jia, X.Y. Zhang, L.J. Su, R. Zhou, Five isomorphic lanthanide metal-organic frameworks constructed from 5-(3-carboxyphenyl)-pyridine-2- 
carboxylic acid and oxalate: synthesis, crystal structures and selective fluorescence sensing for aniline, J. Solid State Chem., (2018) https://doi.org/10.1016/j.jssc.2018.09.004.

22. H. Tong, G. Zhou, L. Wang, X. Jing, F. Wang, J. Zhang, Novel highly selective anion chemosensors based on 2,5-bis(2-hydroxyphenyl)-1,3,4-oxadiazole, Tetrahedron Lett. 44 (2003) 131-134.

23. T. H. Kim, C.H. Lee, C.G. Kwak, M.S. Choi, W.H. Park, T.S. Lee, Bis(2-hydroxyphenyl)1,3,4-oxadiazole derivative for anion sensing and fluorescent patterning, Mol. Cryst. Liq. Cryst. 463 (2007) 255-261.

24. S.H. Mashraqui, S. Sundaram, A.C. Bhasikuttan, S. Kapoor, A.V. Sapre, Novel fluoroionophores incorporating diaryl-1,3,4-oxadiazole and aza-crown ring. Potentially sensitive Mg2+ ion sensor, Sens. \& Actu. B-Chem. 122 (2007) 347-350.

25. J. Ding, M. Day, Novel Highly fluorinated poly(arylene ether-1,3,4-oxadiazole)s, their preparation, and sensory properties to fluoride anion, Macromolecules. 39(2006) 60546062.

26. G. Zhou, Y. Cheng, L. Wang, X. Jing, F. Wang. Novel Polyphenylenes containing phenolsubstituted oxadiazole moieties as fluorescent chemosensors for a fluoride ion, Macromolecules. 38 (2005) 2148-2153.

27. T.H. Kim, H.J. Kim, C.G. Kwak, W.H. Park, T.S. Lee. Aromatic oxadiazole-based conjugated polymers with excited-state intramolecular proton transfer: Their synthesis and sensing ability for explosive nitroaromatic compounds. Polym. Sci., Part A: Polym. Chem. 44 (2006) 2059-2068.

28. A.O. Maslat, M. Abussaud, H. Tashtoush, M.A. Talib, Synthesis, antibacterial, antifungal and genotoxic activity of bis-1,3,4-oxadiazole derivatives Pol. J. Pharmacol. 54 (2002) 55 .

29. G. Ambrosi, P. Rossi, Efficient fluorescent sensors based on 2,5diphenyl $[1,3,4]$ oxadiazole: a case of a specific response to $\mathrm{zn}(\mathrm{ii})$ at physiological $\mathrm{pH}$, Inorg. Chem. 49 (2010) 9940.

30. C.K. Kwak, C.H. Lee, T.S. Lee, A new series of 2,5-bis(4-methylphenyl)-1,3,4-oxadiazole derivatives: their synthesis and fluorescence properties for anion sensors, Tetra. Lett., 48 (2007) 7788-7792.

31. X.Y. Shang, S.J. Wang, X.C. Ge, M. Xiao, Y.Z. Meng, Synthesis and photoluminescent properties of poly(arylene ether)s containing oxadiazole and fluorene moieties, Chem. Phys. 104 (2007) 215. 
32. N. Deshpande and I.A.M. Khazi, synthesis, characterization and optoelectronic investigations of thiophene substituted 1,3,4-oxadiazole derivatives as the fluorescent, International journal of current research. 8 (2016) 38580-38586.

33. J.S. Kadadevarmath, T.P. Giraddi, G.H. Malimath, G.C. Chikkur, Electronic excitation energy quenching of an organic liquid scintillator by carbon tetrachloride in different solvents, Radiant. Meas.26 (1996) 117.

34. Lohit Naik, Imtiyaz Ahamed M. Khazi, and G.H.Malimath, Studies on photosensitization of $\mathrm{TiO}_{2}$ nanoparticles by novel 1,3,4-oxadiazoles derivatives,183(2019)732-741.

35. H.R. Deepa, J. Thipperudrappa, H.M. Suresh Kumar, A study on fluorescence quenching of LD-425 by aromatic amines in 1,4-dioxane-acetonitrile mixtures, J. Lumin. 132 (2012) 1382 .

36. J.S. Kadadevarmath, G.H. Malimath, R.M. Melavanki, N.R. Patil, Static and dynamic model fluorescence quenching of laser dye by carbon tetrachloride in binary mixtures, Spectrochim. Act a Part A.117 (2014) 630-634.

37. J.M. Nirupama., N.I. Khanapurmath, L.S. Chougala, L.A. Shastri, R.F. Bhajantri, M.V. Kulkarni, J.S. Kadadevarmath, Effect of Amino Anilines on the Fluorescence of Coumarin Derivative, Journal of Luminescence, 208 (2019)164-173.

38. R.M. Melavanki, R.A. Kusanur, J.S. Kadadevaramath, M.V. Kulkarni, Quenching mechanisms of 5BAMC by aniline in different solvents using Stern-Volmer plots, J. Lumin.29 (2009) 1298-1303.

39. N.R. Patil, R.M. Melavanki, S.B. Kapatkar, K. Chandrasekhar, N.H. Ayachit, Siva Umapathy, Solvent effect on the fluorescence quenching of biologically active carboxamide by aniline and carbon tetrachloride in different solvents using S-V plots $\mathrm{J}$. Lumin. 132 (2012) 558-565.

40. J. Thipperudrappa, D.S. Biradar, M.T. Lagare, S.M. Hanagodimath, S.R. Inamdar, J.S. Kadadevaramath, Fluorescence quenching of BPBD by aniline in benzene-acetonitrile mixtures, J. Photochem. Photobiol. A: Chem. 177 (2006) 89-93.

41. J.T. Edward, Molecular volumes and the Stokes-Einstein equation, J. Chem. Edu. 47 (1970) 261-270.

42. J.C. Andre, M. Niclause, and W.R. Ware, Kinetics of partly diffusion-controlled reactions. I. Transient and apparent transient effect in fluorescence quenching, Chem. Phys. 28, 371 (1978).

43. H. Zeng and G. Durocher, Analysis of fluorescence quenching in some antioxidants from non-linear Stern-Volmer plots, J. Lumin. 63(1995)75-84. 
44. Joel. Keizer, Diffusion effects on rapid bimolecular chemical reactions, J. Phys. Chem. 87 (1987) $167-180$

45. G.C. Joshi, R. Bhatnagar, S. Doraiswamy, N. Periasamy, Diffusion-controlled reactions: transient effects in the fluorescence quenching of indole and n-acetyl tryptophanamide in water, J. Phys. Chem. 94 (1990) 29082914.

46. C. Tablet, M. Hillebrand, Quenching of the fluorescence of 3-carboxy-5,6-benzocoumarin by aromatic amines, J. Photochem. Photobiol. A Chem. 189 (2007) 73-79.

47. S. Ania, Pavitt, Eric J. Bylaska, and G. Paul. Tratnyek, Oxidation potentials of phenols and anilines: correlation analysis of electrochemical and theoretical values, The Royal Society of Chemistry 2017, DOI: 10.1039/C6EM00694A

48. R.A. Weller, Kinetics of Fluorescence Quenching by Electron and H-atom Transfer, Isr. J. Chem. 8 (1970) 259.

49. Yan-Jun Hu, Yi Liu, Jia-Bo Wang, Xiao-He Xiao, Song-Sheng Qu, Study of the interaction between mono ammonium glycyrrhizinate and bovine serum albumin, J. Pharm. Biomed. Anal. 36 (2004) 915-919.

50. Prof. Bernard Valeur, Molecular Fluorescence: Principles and Applications, 2001, DOI:10.1002/3527600248. 